Original article

\title{
Role of cinacalcet in the treatment of secondary hyperparathyroidism in chronic kidney disease
}

\author{
H.K. Aggarwal, Deepak Jain, Vipin Kaverappa, Sumin Kaushik, Sachin Yadav
}

Department of Medicine, Pt. B.D. Sharma University of Health Sciences, Rohtak (Haryana), India

Received 5 May 2013, Accepted 13 June 2013

(C) 2013, Aggarwal H.K., Jain D., Kaverappa V., Kaushik S., Yadav S.

(C) 2013, Russian Open Medical Journal

\begin{abstract}
Introduction - Secondary hyperparathyroidism (SHPT) is common in patients with chronic kidney disease (CKD) affecting most of the patients in end stage renal disease. Materials and Methods - This prospective case control study was conducted on 50 adult patients of CKD, having individual parathyroid hormone (iPTH) levels $>300 \mathrm{pg} / \mathrm{ml}$. These patients were divided into two groups: Group I ( $=25$ ) received calcitriol in dosage of $0.5 \mu \mathrm{g} /$ day. Group II $(\mathrm{n}=25)$ received cinacalcet in dosage of $30 \mathrm{mg} /$ day and calcitriol $0.5 \mu \mathrm{g} / \mathrm{day}$. The study was carried out for 6 month duration. Results - The mean basal value of iPTH decreased to $246.40 \pm 219.99 \mathrm{pg} / \mathrm{ml}$ at the end of the study from basal value of $482.80 \pm 229.86$ in group II. There was a $43 \%$ decrease in serum iPTH values in group II as opposed to the $14 \%$ decrease in group I $(\mathrm{P}<0.05)$. Serum CaxP decreased by $9 \%$ in group I and by $13 \%$ in group II and there was statistically significant difference at the end of $3^{\text {rd }}$ month as well as at the end of study in cinacalcet group. Conclusion - Cinacalcet is unique in its ability to simultaneously lower PTH, calcium, phosphorus and CaxP in patients with SHPT and thus could become an important component in treatment of CKD patients.
\end{abstract}

Keywords: secondary hyperparathyroidism, chronic kidney disease, cinacalcet, parathyroid hormone, serum calcium, serum phosphorus

Cite as Aggarwal HK, Jain D, Kaverappa V, Kaushik S, Yadav S. Role of cinacalcet in the treatment of secondary hyperparathyroidism in chronic kidney disease. Russian Open Medical Journal 2013; 2: 0309.

Correspondence to Dr. H K Aggarwal. Address: Department of Medicine, PGIMS, Rohtak-124001 (Haryana), India. E-mail: hariaggarwal@rediffmail.com Phone: +91-9416731408

\section{Introduction}

Chronic kidney disease (CKD) is a disease entity associated with premature mortality, decreased quality of life and increased health care expenditure. Disorders of calcium and phosphate metabolism is an important complication in CKD patients which principally affects skeletal system and vascular beds with occasional severe involvement of extra-osseous soft tissues [1]. The term chronic kidney disease, mineral bone disorder (CKDMBD) is used to recognize the broad spectrum of disorders of mineral metabolism in this clinical setting, which develops as a systemic disorder of mineral and bone metabolism as a results of CKD. This can manifest by any one or combination of the following; abnormalities of calcium, phosphorus, parathyroid hormone (PTH) and vitamin $D$ metabolism leading to secondary hyperparathyroidism, renal osteodystrophy, and vascular/soft tissue calcifications [1-3].

Secondary hyperparathyroidism (SHPT) is the most prevalent abnormality detected in CKD [4]. The pathogenesis of secondary hyperparathyroidism consists of relative or absolute deficiency of vitamin $D$ and retention of phosphorus by the kidneys which begin early in the course of CKD when kidney function is reduced to approximately $60 \mathrm{ml} / \mathrm{min} / 1.73 \mathrm{~m}[5,6]$. Elevated serum levels of PTH, phosphorus, and calcium -phosphorus ion product (CaxP) are associated with an increased mortality risk due to various cardiac complications [6-8]. In recognition of this, the National Kidney Foundation Kidney Disease Outcome Quality Initiative (NKFKDOQI) has published treatment goals for these patients [9]. Conventional treatment for SHPT includes calcium supplementation, dietary phosphate restriction, oral phosphatebinding agents, active vitamin D sterols, and parathyroidectomy in patients' refractory to therapy. However, treatment with vitamin $D$ sterols may lead to hypercalcemia and hyperphosphatemia, particularly when used with large doses of calcium containing phosphate binders [10-12].

A significant proportion of hemodialysis patients receiving such treatment have elevated calcium and phosphorus, potentially requiring interruption of treatment that allows disease progression $[13,14]$. A more recent observational study of approximately 4000 dialysis patients found that achievement of the NKF-KDOQI targets remained poor with traditional care. Eleven per cent of these patients had PTH values that averaged 150 to $300 \mathrm{pg} / \mathrm{ml}$ during twelve month of follow-up, and only one per cent of these patients had average values of PTH, calcium, phosphorus, and CaxP over twelve months that were within all four target ranges [15]. Even in patients treated with paracalcitol that may have reduced capacity to enhance intestinal absorption of calcium and phosphorus, more than sixty percent of the patients experienced calcium levels greater than $11 \mathrm{mg} / \mathrm{dl}$ and/or CaxP greater than $75 \mathrm{mg}^{2} / \mathrm{dl}^{2}$ [16]. Consequently, achievement of KDOQI treatment goals is difficult with conventional treatment and novel treatment strategies are required.

The calcium-sensing receptor located on the surface of chief cells in the parathyroid gland is the principal regulator of PTH secretion and therefore is an ideal target for therapies to treat SHPT [17-19]. The calcimimetics have provided an alternative approach to the treatment of SHPT by directly targeting these 
calcium-sensing receptor. These agents increase the extracellular calcium sensitivity of the Calcium sensing receptors to lower circulating PTH levels within 1 to $2 \mathrm{~h}$ of administration $[18,20]$. Cinacalcet, a relatively new calcimimetic agent devoid of problems of the earlier vitamin $D$ analogues, when added to conventional treatment regimens can simultaneously address all four KDOQI targets (Serum $\mathrm{Ca}^{++}$and $\mathrm{PO}_{4}{ }^{3-}$, serum iPTH, CaxP) with less adverse effects $[21,22]$.

The present study has been planned to compare the efficacy of cinacalcet and calcitriol with calcitriol alone, in terms of lowering PTH, calcium phosphate product, serum calcium and serum phosphorous levels in patients of chronic kidney disease with secondary hyperparathyroidism.

\section{Materials and Methods}

The present study was a prospective case control study was conducted on 50 adult patients of age 20-75 years recruited from the Kidney and Dialysis Clinic of our institute. The study was duly approved by the ethical committee of University of Health Sciences. A pre-informed written consent for inclusion in this study was also obtained from all the patients. The study was carried out on adult patients of CKD, with iPTH levels $>300 \mathrm{pg} / \mathrm{ml}$, for a duration of 6 months. Patients were randomized into one of two groups in alternating fashion.

Group I - $(n=25)$ receiving calcitriol in dosage of $0.5 \mu \mathrm{g} /$ day.

Group II $-(n=25)$ receiving cinacalcet in dosage of $30 \mathrm{mg} /$ day and calcitriol $0.5 \mu \mathrm{g} /$ day.

Patients with primary hyperparathyroidism and other causes of secondary hyperparathyroidism and hypercalcemia, such as sarcoidosis and malignancy, patients having any underlying medical condition such as malabsorption syndrome or severe liver disease that might alter the absorption or metabolism of calcitriol, patients with albumin corrected serum calcium concentration less than $8.4 \mathrm{mg} \%$ were excluded from the study. Also excluded were patients with any condition that will, preclude a patient from remaining in the study such as alcohol / drug abuse, psychiatric disorder, pregnancy and patients on inhibitors/inducers of cytochrome $\mathrm{P}_{450}$ (CYP 3A4).

Each patient was subjected to detailed physical examination and investigation at the time of enrollment into the study. They continued to receive anti-hypertensives, supplemental calcium, phosphate binders and diuretics as per their biochemical renal profile and clinical examination. A dialysate calcium concentration of $2.5 \mathrm{meq} / \mathrm{l}$ was used in all patients requiring hemodialysis.

Patients were followed up and examined on monthly basis. Routine investigations including serum calcium levels, serum phosphorous levels and serum calcium phosphorous product were assessed at baseline and during each visit. iPTH levels were measured at the start of study, at 3 months and at the end of study ( 6 months after treatment), by chemiluminescent immuno assay (CLIA) method. Estimated glomerular filtration rate (eGFR) was measured using Modification of Diet in Renal Disease (MDRD) formula. On each visit patient was subjected to a detailed questionnaire for adverse effect profile such as headache, malaise, palpitation, constipation, dyspepsia, allergic reaction, excessive thirst, frequency of micturition and abdominal pain.

The results were analyzed by unpaired t-test and various values were expressed as Mean $\pm 2 S D$.
Table 1. Baseline parameters of case and control groups

\begin{tabular}{lccc}
\hline Parameters & Group I & Group II & P-level \\
\hline Hemoglobin (gm \%) & $8.27 \pm 1.08$ & $8.15 \pm 1.20$ & $>0.05$ \\
Serum potassium (meq/L) & $4.37 \pm 0.65$ & $4.15 \pm 0.87$ & $>0.05$ \\
Serum sodium (meq/L) & $141.00 \pm 6.23$ & $139.48 \pm 5.28$ & $>0.05$ \\
Blood urea (mg \%) & $140.56 \pm 48.99$ & $151.32 \pm 43.14$ & $>0.05$ \\
Blood sugar fasting (mg\%) & $108.08 \pm 73.88$ & $89.28 \pm 2.33$ & $>0.05$ \\
Blood sugar post prandial & $117.36 \pm 26.0$ & $111.08 \pm 28.35$ & $>0.05$ \\
$\begin{array}{l}\text { (mg\%) } \\
\text { Serum creatinine (mg \%) }\end{array}$ & $4.92 \pm 1.93$ & $5.52 \pm 1.41$ & $>0.05$ \\
Serum calcium (mg \%) & $9.08 \pm 0.54$ & $9.20 \pm 0.48$ & $>0.05$ \\
Serum phosphorous (mg \%) & $6.14 \pm 0.79$ & $5.77 \pm 0.32$ & $>0.05$ \\
$\begin{array}{l}\text { Serum calcium phosphate } \\
\text { product (mg } / \mathrm{dl}^{2} \text { ) }\end{array}$ & $55.69 \pm 7.86$ & $53.00 \pm 5.12$ & $>0.05$ \\
GFR (ml/min) & $17.88 \pm 4.21$ & $18.00 \pm 3.99$ & $>0.05$ \\
\hline
\end{tabular}

Table 2. Variations in mean blood urea, serum creatinine, corrected serum calcium and serum phosphorous levels

\begin{tabular}{lccc}
\hline Parameters & Group I & Group II & P-level \\
\hline Blood Urea Levels (mg\%) & & & \\
- - Basal & $140.56 \pm 48.99$ & $144.08 \pm 41.21$ & $>0.05$ \\
$-3^{\text {rd }}$ month & $129.40 \pm 43.67$ & $153.92 \pm 49.43$ & $>0.05$ \\
$-6^{\text {th }}$ month & $133.52 \pm 44.55$ & $145.28 \pm 41.86$ & $>0.05$ \\
\hline Serum Creatinine Levels (mg\%) & & & \\
- Basal & $4.92 \pm 1.93$ & $5.52 \pm 1.41$ & $>0.05$ \\
$-3^{\text {rd }}$ month & $4.82 \pm 1.95$ & $5.78 \pm 1.45$ & $>0.05$ \\
$-6^{\text {th }}$ month & $4.96 \pm 2.02$ & $6.00 \pm 1.69$ & $>0.05$ \\
\hline Correlated Serum Calcium Levels $(\mathrm{mg} \%)$ & & \\
- - Basal & $9.08 \pm 0.54$ & $9.20 \pm 0.48$ & $>0.05$ \\
\hline$-3^{\text {rd }}$ month & $8.95 \pm 0.52$ & $8.85 \pm 0.26$ & $>0.05$ \\
$-6^{\text {th }}$ month & $8.80 \pm 0.79$ & $8.60 \pm 0.27$ & $>0.05$ \\
\hline Serum Phosphorus Levels (mg\%) & & & \\
- Basal & $6.14 \pm 0.79$ & $5.77 \pm 0.32$ & $>0.05$ \\
$-3^{\text {rd }}$ month & $5.96 \pm 0.77$ & $5.38 \pm 0.52$ & $<0.05$ \\
$-6^{\text {th }}$ month & $5.78 \pm 0.79$ & $5.35 \pm 0.48$ & $<0.05$ \\
\hline
\end{tabular}

\section{Results}

The mean age of the patients in group I was $(47.28 \pm 14.47)$ with a range of $20-75$ years. The patients of group II had a mean age of $(49.24 \pm 13.21)$ with a range of $20-65$ years. Majority of patients were above 40 years of age. Seven patients in group I and eight patients in group II were younger than 40 years. Male female ratio was 2.1:1. Baseline renal parameters were comparable in both the groups (Table 1).

Chronic glomerulonephritis was the most common cause of chronic kidney disease, followed by other causes including diabetic nephropathy, hypertensive nephropathy, adult polycystic kidney disease, obstructive uropathy and renal amyloidosis.

The blood urea level almost remained constant during the study and the difference in the value was not statistically significant between the two groups. However; there was an increase in serum creatinine value in group II, while it remained constant in group I. The difference between values of serum creatinine in two groups was not significant at any given point of time.

The mean basal values of corrected serum calcium level were $9.20 \pm 0.48$ and $9.08 \pm 0.54$ in group II and group I respectively. There was slow decrease in serum calcium levels during the study in both groups and at the end of the study were $8.60 \pm 0.27$ and $8.80 \pm 0.79$ respectively. Although the mean decrease was around $7 \%$ in group II and $3 \%$ in group I, the difference between values of serum 
calcium in two groups were not significant at any given point of time. There was statistically significant difference in serum phosphorus levels in group II and group I at the end of $3^{\text {rd }}$ month and at the end of study. The mean serum phosphorous level decreased from $5.77 \pm 0.32$ to $5.35 \pm 0.48$ in group II and from $6.14 \pm 0.79$ to $5.78 \pm 0.79$ in group I. Although the corresponding decrease in serum phosphorous levels were $7 \%$ and $5 \%$ respectively, the proportions of patients achieving the targeted phosphorus level $(<5.5 \mathrm{mg} / \mathrm{dl})$ was higher in group II (76\%) than in group I (44\%) with $\mathrm{P}<0.05$ (Table 2 ).

Serum calcium phosphate product decreased by $13 \%$ in group II and by $9 \%$ in group I, which was statistically significant both at the end of $3^{\text {rd }}$ month and at the end of study. The mean calcium phosphate product decreased from $53.00 \pm 5.12$ at baseline, to $47.82 \pm 4.30$ and $46.05 \pm 4.43$ at 3 months and 6 months respectively, in group II; whereas the corresponding values in group I were $55.69 \pm 7.86,53.08 \pm 7.29$, and $50.75 \pm 7.02$ respectively. All the seven patients of group II who were having CaxP level $>55 \mathrm{mg}^{2} / \mathrm{dl}^{2}$ achieved the targeted CaxP level $<55 \mathrm{mg}^{2} / \mathrm{dl}^{2}$ (100\%) whereas in group I only $76 \%$ patients achieved this target level with conventional care (Table 3, Figure 1).

The mean IPTH levels decreased progressively throughout the study in both the groups, but the decrease was modest in group I. iPTH levels decreased from $482.80 \pm 229.86$ at baseline to $246.40 \pm 219.99$ at the end of study in group II, and from $490.52 \pm 271.76$ to $420.80 \pm 288.61$ over the same interval for group I patients. There was a $43 \%$ decline in serum iPTH values in group II as opposed to the $14 \%$ decrease in group I. The median iPTH values at baseline and at the end of the study were 421 and 191 for group II; whereas for group I it was 467 and 374 respectively. The difference in serum iPTH level between group I and group II at the end of study was statistically significant $(\mathrm{P}<0.05)$ (Table 3 , Figure 2).

Among 25 patients in group II, 21 (84\%) achieved target goal for iPTH $(150-300 \mathrm{pg} / \mathrm{ml})$, while in patients of group I only $11(44 \%)$ achieved this target at the end of study. Among 25 patients in group II, 14 (56\%) achieved greater than 50\% reduction in serum iPTH levels at the end of study whereas only one out of 25 (4\%) group I patients achieved this target at the end of study.

None of the patients in any group developed significant side effects so as to warrant reduction in dosage or withdrawal of the drug. The observations of the study revealed that cinacalcet along with calcitriol reduces parathyroid hormone levels significantly with a relatively low incidence of hypercalcemia compared to calcitriol alone without any significant side effect.

\section{Discussion}

Traditional therapies for SHPT are limited by adverse effect profile that may place patients at higher risk for vascular calcification. Vitamin D increases calcium and phosphorus absorption from the intestine increasing the incidence of hypercalcemia and hyperphosphatemia, frequently necessitating treatment interruptions which eventually result in inadequate control of PTH and disease progression [23, 24]. Poor control of mineral metabolism is also associated with a higher risk for death, calcification of the coronary arteries and aorta, increased arterial stiffness, and cardiac valve calcification [1-3, 8]. A recent report from a large international dialysis database demonstrated that among hemodialysis (HD) patients in five European countries, hospitalization rates for cardiovascular-related causes were as high as 26\% [25]. Despite lack of definitive link between PTH and increased cardiovascular disease risk, there are observational data that illustrate a strong association between cardiac mortality and serum phosphorus and calcium phosphate product (CaxP) levels. Hyperphosphatemia is often closely associated with SHPT in the context of increased mortality in dialysis patients. The adjusted relative risk of death was found to be higher with serum phosphorus levels greater than $6.5 \mathrm{mg} / \mathrm{dl}$ and CaxP product levels greater than $72 \mathrm{mg}^{2} / \mathrm{dl}^{2}$. This translates into a 1.27 and 1.34 relative mortality risk for elevated serum phosphorus and CaxP product levels, respectively [26].

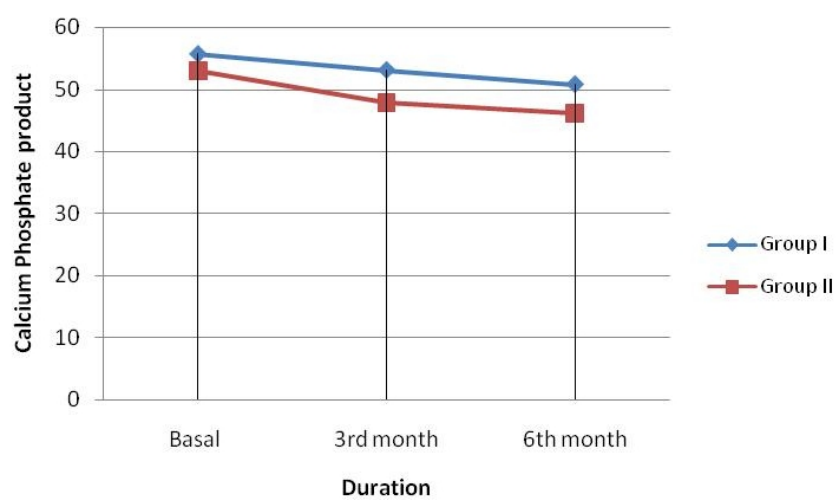

Figure 1. Variation in calcium phosphate product $(\mathrm{CaxP})$ during the study. The decrease in CaxP was statistically significant $(P<0.05)$ at 3 months as well as at the end of the study ( 6 months).

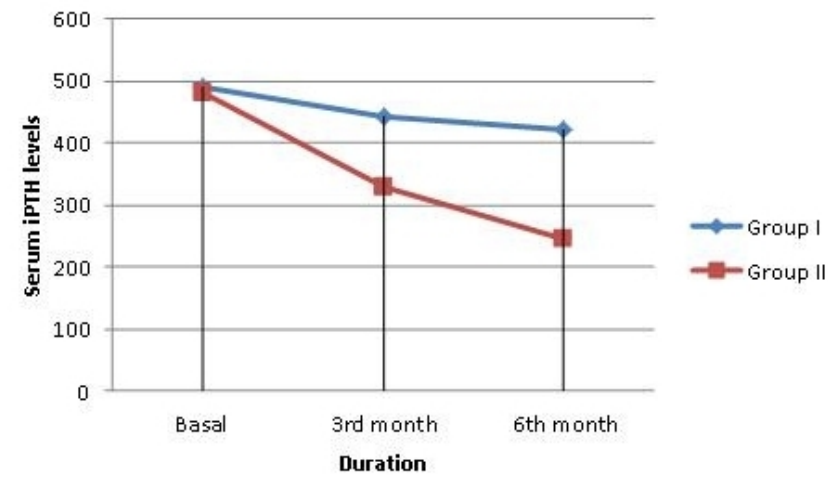

Figure 2. Variations in serum iPTH levels during the study.

The decrease in serum levels was statistically significant $(P<0.05)$ at the end of the study.

Table 3. Variation in calcium phosphate product and serum iPTH levels

\begin{tabular}{|c|c|c|c|}
\hline Parameters & Group I & Group II & P-level \\
\hline \multicolumn{4}{|c|}{ Serum Calcium Phosphate Product $\left(\mathrm{mg}^{2} / \mathrm{dl}^{2}\right)$} \\
\hline - Basal & $55.69 \pm 7.86$ & $53.00 \pm 5.12$ & $>0.05$ \\
\hline$-3^{\text {rd }}$ month & $53.08 \pm 7.29$ & $47.82 \pm 4.30$ & $<0.05$ \\
\hline$-6^{\text {th }}$ month & $50.75 \pm 7.02$ & $46.05 \pm 4.43$ & $<0.05$ \\
\hline \multicolumn{4}{|c|}{ Serum Intact PTH Levels $(\mathrm{pg} / \mathrm{ml})$} \\
\hline - Basal & $490.52 \pm 271.76$ & $482.80 \pm 229.86$ & $>0.05$ \\
\hline$-3^{\text {rd }}$ month & $443.80 \pm 271.07$ & $329.52 \pm 204.76$ & $>0.05$ \\
\hline$-6^{\text {th }}$ month & $420.80 \pm 288.61$ & $246.40 \pm 219.99$ & $<0.05$ \\
\hline
\end{tabular}


There is thus considerable interest in identifying therapeutic alternatives that control secondary hyperthyroidism while limiting these side effects. The calcium-sensing receptor regulates the secretion of parathyroid hormone. Calcimimetic agents increase the sensitivity of the calcium-sensing receptors to extracellular calcium ions, inhibit the release of parathyroid hormone, and lower parathyroid hormone levels within a few hours after adminnstration [21, 28-30]. This mechanism of action differs from that of vitamin $D$ sterols, which diminish the transcription of the parathyroid hormone gene and hormone synthesis over a period of many hours or several days. The KDOQI guidelines for the management of bone metabolism and disease in CKD aim to reduce the risk of vascular calcification and bone disease through the control of biochemical parameters. Cinacalcet is unique in its ability to simultaneously lower PTH, calcium, phosphorus and CaxP in patients with SHPT and thus could become an important component in treatment. Because cinacalcet is not associated with elevations in calcium and phosphorus, treatment strategies that include cinacalcet may allow better achievement of the KDOQI targets and possibly reduce complications associated with SHPT. In addition, lowering calcium and phosphorus levels with cinacalcet may allow the use of physiologic doses of vitamin D sterols with a reduced risk for occurrence of hypercalcemia and hyperphosphatemia.

The present study showed that significantly greater proportion of subjects receiving cinacalcet along with calcitriol achieved a PTH $\leq 300 \mathrm{pg} / \mathrm{ml}$ and CaxP $<55 \mathrm{mg}^{2} / \mathrm{dl}^{2}$. The results of this study demonstrate that once-daily oral cinacalcet is effective and safe for the management of SHPT in patients who are receiving HD. Cinacalcet was superior to control treatment for iPTH reduction in this study, including mean percentage reduction in iPTH from baseline. Despite the high prevalence of patients with severe disease at baseline, $74 \%$ of cinacalcet treated patients in this study achieved a mean iPTH level $\leq 300 \mathrm{pg} / \mathrm{ml}$, the upper limit of the PTH target range recently set by the NKF-KDOQI guidelines. The decrease in IPTH values affected by cinacalcet was accompanied by reductions in mean CaxP, calcium, and phosphorus levels consistent with previous studies. The results were consistent with OPTIMA algorithm where $71 \%$ of patients achieved the primary end point of a mean iPTH value $\leq 300 \mathrm{pg} / \mathrm{ml}$ and $82 \%$ achieving either mean $\mathrm{iPTH} \leq 300 \mathrm{pg} / \mathrm{ml}$ or a $\geq 30 \%$ mean reduction from baseline [31]. Similar results were obtained in ACHIEVE study where median iPTH levels declined progressively among the study group. Significantly greater proportion of subjects receiving Cinacalcet achieved a PTH $\leq 300 \mathrm{pg} / \mathrm{ml}$ (44 versus 23), with concurrent KDOQI defined control of PTH, calcium, phosphorus, and CaxP.32 In a study by Geoffrey et al., iPTH levels were significantly lower in patients given Cinacalcet than in those receiving placebo. Mean parathyroid hormone decreased by $43 \%$ in Cinacalcet group but increased by $9 \%$ in placebo group. The CaxP declined by $15 \%$ in the Cinacalcet group while it remained unchanged in the placebo group. It was concluded that Cinacalcet effectively reduced PTH levels independently of disease severity or changes in vitamin D sterol dose [21].

\section{Conclusion}

There is less incidence of hypercalcemia with use of cinacalcet and calcitriol than calcitriol alone in SHPT associated with chronic kidney disease. This study overall supports efficacy of cinacalcet with calcitriol as a therapeutic strategy for SHPT. Although caution must be exercised, since over suppressed PTH levels may not be beneficial and indeed could be associated with increased risk of low bone turn over disease or other adverse outcomes. Together these findings underscore the challenges of achieving and maintaining PTH levels within a relatively narrow therapeutic target range. However; long term follow-up studies have to be undertaken to assess the efficacy of cinacalcet with calcitriol in the treatment of secondary hyperparathyroidism.

Conflict of interest: none declared.

\section{Reference}

1. Block GA, Hulbert-Shearon TE, LevinNW, Port FK. Association of serum phosphorusand calcium $\times$ phosphate product with mortality risk in chronic hemodialysis patients: A national study. Am J Kidney Dis 1998; 31: 607-617. (PMID: 9531176)

2. Goodman WG, Goldin J, Kuizon BD, Yoon C, Gales B, Sider D, et al. Coronary-artery calcification in young adults with end-stage renal disease who are undergoing dialysis. N Engl J Med 2000; 342: 14781483. (PMID: 10816185) (doi: 10.1056/NEJM200005183422003)

3. Ganesh SK, Stack AG, Levin NW, Hulbert-Shearon T, Port FK. Association of elevated serum $\mathrm{PO}(4), \mathrm{Ca} \times \mathrm{PO}(4)$ product, and parathyroid hormone with cardiac mortality risk in chronic hemodialysis patients. J Am Soc Nephrol 2001; 12: 2131-2138. (PMID: 11562412)

4. Sherrard DJ, Hercz G, Pei Y, Maloney NA, Greenwood C, Manuel A, et al. The spectrum of bone disease in end stage renal failure. An evolving disorder. Kidney Int 1993; 43: 436-442. (PMID: 8441240)

5. Coresh J, Astor BC, Greene T, Eknoyan G, Levey AS. Prevalence of chronic kidney disease and decreased kidney function in the adult US population: Third National Health and Nutrition Examination Survey. Am J Kidney Dis 2003; 41(1): 1-12. (PMID: 12500213)

6. Llach F, Yudd M. Pathogenic, clinical, and therapeutic aspects of secondary hyperparathyroidism in chronic renal failure. Am J Kidney Dis 1998; 32(2): 3-12. (PMID: 9808139)

7. Raggi P, Boulay A, Chasan-Taber S,Amin N, Dillon M, Burke SK, et al. Cardiac calcification in adult hemodialysis patients: a link between end-stage renal disease and cardiovascular disease? J Am Coll Cardiol 2002; 39: 695-701. (PMID: 11849871)

8. Ribeiro S, Ramos A, Brandao A,Rebelo JR, Guerra A, Resina C, et al. Cardiac valve calcification in haemodialysis patients: role of calciumphosphate metabolism. Nephrol Dial Transplant 1998; 13: 2037-2040. (PMID: 9719161) (doi: 10.1093/ndt/13.8.2037)

9. National Kidney Foundation (2002). KDOQI clinical practice guidelines for chronic kidney disease". Retrieved 2008-06-29.

10. Martin KJ, Gonzalez EA, Gellens M, Hamm LL, Abboud H, Lindberg J. 19-Nor-1-alpha-25-dihydroxyvitamin D2 (Paricalcitol) safely and effectively reduces the levels of intact parathyroid hormone in patients on hemodialysis. J Am Soc Nephrol 1998; 9: 1427-1432. (PMID: 9697664)

11. Maung HM, Elangovan L, Frazao JM, Bower JD, Kelley BJ,Acchiardo SR, et al. Efficacy and side effects of intermittentintravenous and oral doxercalciferol $\left(1 \alpha\right.$-hydroxyvitamin $\left.D_{2}\right)$ in dialysis patients with secondary hyperparathyroidism: A sequential comparison. Am J Kidney Dis 2001; 37: 532-543. (doi: 10.1016/S0272-6386(01)80010-X)

12. Johnson CA, McCarthy J, Bailie GR, Deane J, Smith S. Analysis of renal bone disease treatment in dialysis patients. Am J Kidney Dis 2002; 39: 1270-1277. (PMID: 12046041) (doi: 10.1053/ajkd.2002.33401)

13. Malluche H, Faugere MC. Renal bone disease 1990: an unmet challenge for the nephrologist. Kidney Int 1990; 38(2): 193-211. (PMID: 2205749)

14. Morii $\mathrm{H}$, Inoue $\mathrm{T}$, Nishijima $\mathrm{T}$, Tomokuni $\mathrm{T}$, Ishikawa $\mathrm{T}$, Moriya $\mathrm{K}$, et al. Management of calcium and bone abnormalities in hemodialysis patients. Semin Nephrol 2004; 24(5): 446-448. (PMID: 15490408) (doi: 10.1016/j.semnephrol.2004.06.016) 
15. Kim J, Pisoni RL, Danese MD, Satayathum S, Klassen P, Young EW. Achievement of proposed NKF-K/DOQI bonemetabolism and disease guidelines: Results from the dialysisoutcomes and practice patterns study (DOPPS) [Abstract]. J Am SocNephrol 2003; 13: 270.

16. Sprague SM, Llach F, Amdahl M, Taccetta C, Batlle D. Paricalcitol versus calcitriol in the treatment of secondary hyperparathyroidism. Kidney Int 2003; 63(4): 1483-1490. (PMID: 12631365) (doi: 10.1046/j.15231755.2003.00878.x)

17. Brown EM, Gamba G, Riccardi D, Lombardi M, Butters R, Kifor O, et al. Cloningand characterization of an extracellular $\mathrm{Ca}(2+)$-sensing receptorfrom bovine parathyroid. Nature 1993; 366: 575-580. (PMID: 8255296) (doi: 10.1038/366575a0)

18. Nemeth EF, Steffey ME, Hammerland LG, Hung BC, VanWagenen BC, DelMar EG, et al. Calcimimetics with potent and selective activity on the parathyroid calcium receptor. Proc Natl Acad Sci USA 1998; 95: 4040-4045. (PMID: 9520489) (PMCID: PMC19959)

19. Nemeth EF, Heaton WH, Miller M, Fox J, Balandrin MF, Van Wagenen $\mathrm{BC}$, et al. Pharmacodynamics of the type II calcimimetic compound Cinacalcet HCl. J Pharmacol Exp Ther 2004; 308: 627-635. (PMID: 14593085) (doi: 10.1124/jpet.103.057273)

20. Joy MS, Kshirsagar AV, Franceschini N. Calcimimetics and the treatment of primary and secondary hyperparathyroidism. Ann Pharmacother 2004; 38(11): 1871-1880. (PMID: 15479778) (doi: 10.1345/aph.1D108)

21. Block GA, Martin KJ, de Francisco AL, Turner SA, Avram MM, Suranyi $M G$, et al. Cinacalcet for secondary hyperparathyroidism in patients receiving hemodialysis. N Engl J Med 2004; 350(15): 1516-1525. (PMID: 15071126)

22. Lindberg JS, Culleton B, Wong G, Borah MF, Clark RV, Shapiro WB, et al. Cinacalcet $\mathrm{HCl}$, an oral calcimimetic agent for the treatment of secondary hyperparathyroidism in hemodialysis and peritoneal dialysis: a randomized, double-blind, multicenter study. J Am Soc Nephrol 2005; 16(3): 800-807. (doi: 10.1681/ASN.2004060512) (PMID: 15689407)

23. Goodman WG. Recent developments in the management of secondary hyperparathyroidism. Kidney Int 2001; 59: 1187-201. (PMID: 11231381) (doi: 10.1046/j.1523-1755.2001.0590031187.x)

24. Locatelli F, Cannata-Andia J, Drueke T, Horl W, Fouque D, Heimburger $O$, et al. Management of disturbances of calcium and phosphate metabolism in chronic renal insufficiency, with emphasis on the control of hyperphosphatemia. Nephrol Dial Transplant 2002; 17: 723-731. (doi: 10.1093/ndt/17.5.723)

25. Rayner HC, Pisoni RL, Bommer J, Canaud B, Hecking E, Locatelli F, et al. Mortality and hospitalization in haemodialysis patients in five European countries: Results from the Dialysis Outcomes and Practice Patterns Study (DOPPS). Nephrol Dial Transplant 2004; 19: 108-120. (PMID: 14671046) (doi: 10.1093/ndt/gfg483)

26. Levin NW, Hoenich NA. Consequences of hyperphosphatemia and elevated levels of the calcium-phosphorus product in dialysis patients. Curr Opin Nephrol Hypertens 2001; 10(5): 563-568. (PMID: 11496047)

27. Goodman WG, Frazao JM, Goodkin DA, Turner SA, Liu W, Coburn JW. A calcimimetic agent lowers plasma parathyroid hormone levels in patients with secondary hyperparathyroidism. Kidney Int 2000; 58(1): 436-445. (PMID: 10886592) (doi: 10.1046/j.1523-1755.2000.00183.x)

28. Goodman WG, Hladik GA, Turner SA, Blaisdell PW, Goodkin DA, Liu W, et al. The Calcimimetic agent AMG 073 lowers plasma parathyroid hormone levels in hemodialysis patients with secondary hyperparathyroidism. J Am Soc Nephrol 2002; 13(4): 1017-1024. (PMID: 11912261)

29. Quarles LD. Extracellular calcium-sensing receptors in the parathyroid gland, kidney, and other tissues. Curr Opin Nephrol Hypertens 2003; 12(4): 349-355. (PMID: 12815330)

30. Drüeke TB. Modulation and action of the calcium-sensing receptor. Nephrol Dial Transplant 2004; 19(5): 20-26. (PMID: 15284356) (doi: 10.1093/ndt/gfh1052)
31. Messa P, Macário F, Yaqoob M, Bouman K, Braun J, von Albertini B, et al. The OPTIMA study: assessing a new cinacalcet (Sensipar/Mimpara) treatment algorithm for secondary hyperparathyroidism. Clin J Am Soc Nephrol 2008; 3(1): 36-45. (PMID: 18178780) (PMCID: PMC2390975)

32. Fishbane S, Shapiro WB, Corry DB, Vicks SL, Roppolo M, Rappaport K, et al. Cinacalcet $\mathrm{HCl}$ and Concurrent Low-dose Vitamin D Improves Treatment of Secondary Hyperparathyroidism in Dialysis Patients Compared with Vitamin D Alone: The ACHIEVE Study Results. Clin J Am Soc Nephrol 2008; 3(6): 1718-1725. (PMID: 18945995) (PMCID: PMC2572296) (doi: 10.2215/CJN.01040308)

\section{Authors:}

H.K. Aggarwal - Head Department of Medicine IV and Division of Nephrology, Department of Medicine, Pt. B.D. Sharma University of Health Sciences, Rohtak (Haryana), India;

Deepak Jain - Assistant Professor, Department of Medicine, Pt. B.D. Sharma University of Health Sciences, Rohtak (Haryana), India;

Vipin Kaverappa - Resident, Department of Medicine, Pt. B.D. Sharma University of Health Sciences, Rohtak (Haryana), India;

Sumin Kaushik - Senior Resident, Department of Medicine, Pt. B.D. Sharma University of Health Sciences, Rohtak (Haryana), India;

Sachin Yadav - Resident, Department of Medicine, Pt. B.D. Sharma University of Health Sciences, Rohtak (Haryana), India. 